\title{
cappuccino, a Drosophila maternal effect gene required for polarity of the egg and embryo, is related to the vertebrate limb deformity locus
}

\author{
Steven Emmons, Huy Phan, John Calley, Wenliang Chen, Brian James, and Lynn Manseau' \\ Department of Molecular and Cellular Biology, University of Arizona, Tucson, Arizona 85721 USA
}

\begin{abstract}
We report the molecular isolation of cappuccino (capu), a gene required for localization of molecular determinants within the developing Drosophila oocyte. The carboxy-terminal half of the capu protein is closely related to that of the vertebrate limb deformity locus, which is known to function in polarity determination in the developing vertebrate limb. In addition, capu shares both a proline-rich region and a 70-amino-acid domain with a number of other genes, two of which also function in pattern formation, the Saccharomyes cerevisiae BNI1 gene and the Aspergillus FigA gene. We also show that capu mutant oocytes have abnormal microtubule distributions and premature microtubule-based cytoplasmic streaming within the oocyte, but that neither the speed nor the timing of the cytoplasmic streaming correlates with the strength of the mutant allele. This suggests that the premature cytoplasmic streaming in capu mutant oocytes does not suffice to explain the patterning defects. By inducing cytoplasmic streaming in wild-type oocytes during mid-oogenesis, we show that premature cytoplasmic streaming can displace staufen protein from the posterior pole, but not gurken mRNA from around the oocyte nucleus.
\end{abstract}

[Key Words: Drosophila; cappuccino; pattern formation; cytoplasmic streaming; maternal effect; oogenesis; formins]

Received July 5, 1995; revised version accepted August 25, 1995.

The developing Drosophila oocyte is an excellent model system for studying the establishment of polarity within a single cell because the embryonic anterior-posterior and dorsal-ventral axes are initially organized within the oocyte. Anterior-posterior axis formation of the larva involves three pathways within the oocyte: one that establishes the anterior end, one at the posterior end to establish the abdomen and pole cells, and one at both termini of the oocyte to establish the ends /for reviews, see Manseau and Schüpbach 1989a and Nüsslein-Volhard et al. 1987). The larval anterior is established during oogenesis through localization of the bicoid mRNA to the anterior end of the oocyte (Berleth et al. 1988; Driever and Nüsslein-Volhard 1988a,b). Formation of the abdomen and pole cells requires localization of a large number of molecular determinants to the posterior pole of the developing oocyte (vasa protein, Hay et al. 1988; Lasko and Ashburner 1990; oskar mRNA and protein, Ephrusso et al. 1991; Kim-Ha et al. 1991; Smith et al. 1992; staufen protein, St. Johnston et al. 1991; tudor protein, Bardsley et al. 1993, nanos mRNA and protein, Wang and Lehmann 1991; Ephrussi and Lehmann 1992;

${ }^{1}$ Corresponding author.
Smith et al. 1992; germ cell-less mRNA, Jongens et al. 1994). The termini of the larva are marked during oogenesis by a signaling process between the oocyte and the surrounding epithelium of follicle cells (Stevens et al. 1990; Savant-Bhonsale and Montell 1993).

The first known step in dorsal-ventral axis formation is the localization of the oocyte nucleus to the dorsal anterior corner of the oocyte. gurken mRNA, which encodes a transforming growth factor- $\alpha$ (TGF- $\alpha$ )-like protein, is then localized adjacent to the oocyte nucleus (Neuman-Silberberg and Schüpbach 1993). Presumably, the encoded gurken protein is at a higher level on the dorsal side of the oocyte where it is thought to serve as a ligand for the EGF-receptor (encoded by torpedo) (Price et al. 1989; Schejter and Shilo 1989) in the surrounding epithelium of follicle cells. This signaling process initiates a cascade of differential activities in the follicle cells on the dorsal and ventral sides of the oocyte. This information in the follicle cells is eventually communicated back to the oocyte or its derivative, the egg, to establish the dorsal-ventral axis of the developing embryo (Stein et al. 1991).

cappuccino (capu) and spire (spir) are unusual among maternal effect genes involved in pattern formation in Drosophila in that they affect both anterior-posterior 
and dorsal-ventral axis formation during oogenesis. Their effects on the anterior-posterior axis make them members of the posterior group, having abnormal abdominal segmentation and lacking pole cells and polar granules. In the dorsal-ventral axis, they have been described as producing dorsalized eggs and embryos (Manseau and Schüpbach 1989b). By studying capu and spir, we hoped to gain insights into the common features of these two pathways that are, for the most part, genetically separate.

The apparent defect in capu and spir, common to both of these pathways, is that molecular determinants are not correctly localized within the developing oocyte. The posterior group phenotype results from the lack of localization of components of the polar granules to the posterior pole. In fact, capu and spir are the most upstream genes known to be required for localization of molecular determinants to the posterior pole, being required for proper localization of all components of the polar granules (Manseau and Schüpbach 1989b; Lasko and Ashburner 1990; Ephrussi et al. 1991; Kim-Ha et al. 1991; St. Johnston et al. 1991; Wang and Lehmann 1991; Bardsley et al. 1993). The dorsalized phenotype is presumed to result from the mislocalization of gurken mRNA along the entire anterior end of the oocyte (Neuman-Silberberg and Schüpbach 1993).

Because capu and spir affect localization of determinants in two separate pathways, it was suggested that the cytoskeleton is altered in mutant oocytes (Manseau and Schüpbach 1989b). The cytoskeleton is important throughout oogenesis. During later oogenesis, there are two major cytoskeletal movements. At stage 11, the nurse cells undergo contractions and dump their contents into the oocyte through the ring canals. This process is microfilament-dependent as it is inhibited by cytochalasins (Gutzeit 1986b). A number of components of the actin cytoskeleton that function in this process in the nurse cells or ring canals have been identified |Cooley et al. 1992; Yue and Spradling 1992; Bryan et al. 1993; Xue and Cooley 1993; Bryan et al. 1993; Cant et al. 1994; Mahajan-Miklos and Cooley 1994; for review, see Knowles and Cooley 1994). During the rapid transfer of cytoplasm from the nurse cells into the oocyte, microtubule-dependent cytoplasmic streaming, inhibitable by colcemid, occurs within the oocyte (Gutzeit 1986a). It is thought that this movement within the oocyte is necessary to mix the oocyte cytoplasm with the rapidly entering nurse cell cytoplasm. Coincident with the ooplasmic streaming, microtubules bundle within the oocyte (Theurkauf et al. 1992). Microtubules are also required for the establishment or maintenance of the dorsal-anterior localization of the oocyte nucleus (Koch and Spitzer 1983; Gutzeit 1986a).

Here, we report the molecular isolation of capu. Sequence analysis of capu indicates that the carboxy-terminal half of the protein is closely related to that encoded by the vertebrate limb deformity (ld) locus. In addition, capu shares two small domains of similarity to genes from yeast, Aspergillus, and Drosophila, some of which also function in polarization. Analysis of capu mutant oocytes suggests that the microtubule cytoskeleton is misregulated, resulting in premature microtubule bundling at the cortex of the oocyte and premature microtubule-dependent cytoplasmic streaming within the oocyte. Careful analysis of an allelic series suggests that the premature streaming alone can not explain all of the patterning defects. In support of this argument we show that the induction of premature, microtubule-based streaming in wild-type oocytes does not sweep away all previously localized molecular determinants.

\section{Results}

\section{Genetic fine mapping of capu}

Previous genetic analysis had mapped capu to the polytene chromosomal region 24C3,4-24D3,4 (Manseau and Schüpbach 1989b). This localization is based on complementation analysis with deficiencies that break in the region of capu. To narrow the location of capu within this region, the gene was mapped genetically with respect to a white $e^{+}\left(\mathrm{w}^{+}\right)$transposable element in polytene chromosome region $24 \mathrm{D} 1,2\left\langle\mathrm{P}\left[w^{+}\right]\right)$. To do this, we screened 23,000 chromosomes for recombination events between the $\mathrm{P}\left[\mathrm{W}^{+}\right]$element and a mutant capu allele, $c a p u^{E E}$ and identified 17 females carrying $\mathrm{P}\left[\mathrm{W}^{+}\right]$-capu recombinant chromosomes (see Fig. 1). To determine whether capu lies proximal or distal to the $\mathrm{P}\left[\mathrm{w}^{+}\right]$element, we used a restriction fragment length polymorphism (RFLP) proximal to the capu region in polytene chromosome region $26\left(\mathrm{RFLP}^{\mathrm{A}}\right.$ and $\left.\mathrm{RFLP}^{\mathrm{A}}\right)$ ) as a distant flanking marker. If capu lies distal to the $\mathrm{P}\left[\mathrm{W}^{+}\right]$element, then recombinant chromosomes bearing both capu and the $\mathrm{P}\left[\mathrm{w}^{+}\right]$element would carry RFLPA . Alternatively, if capu lies proximal to the $\mathrm{P}\left[\mathrm{W}^{+}\right]$then, then these recombinant chromosomes would carry RFLP $^{\mathbf{A}^{\prime}}$. Southern blots of genomic DNA isolated from single recombinant flies were analyzed, and of the two recombinant chromosomes examined, both were found to carry RFLP ${ }^{A^{\prime}}$, indicating that capu lies proximal to the $\mathrm{P}\left[w^{+}\right]$element.

A chromosomal walk through this region was initiated from clones flanking the $\mathrm{P}\left[\mathrm{w}^{+}\right]$element (generously provided by Tulle Hazelrigg, Columbia University, New York). To locate the capu gene within the $100-\mathrm{kb}$ chromosomal walk shown in Figure $1 \mathrm{C}$, the $\mathrm{P}\left[\mathrm{W}^{+}\right]$-capu recombinant chromosomes were analyzed for RFLPs found within the walk. Thirteen $\mathrm{P}\left[\mathrm{w}^{+}\right]-$capu recombinants carried a capu chromosome RFLP $\left(\right.$ RFLP $\left.^{\mathrm{B}^{\prime}}\right)$ identified by phage clone AZ3M-6A, while one recombinant carried the $\mathrm{P}\left[\mathrm{w}^{+}\right]$RFLP $\left(\mathrm{RFLP}^{\mathrm{B}}\right)$. Because the distance between the $\mathrm{P}\left[\mathrm{w}^{+}\right.$cbr element and the RFLP identified by AZ3M$6 \mathrm{~A}$ was known to be $\sim 38 \mathrm{~kb}$, this suggested that capu lies $\sim 3 \mathrm{~kb}(38 \mathrm{~kb} / 13$ recombinants $=3 \mathrm{~kb} / 1$ recombinant) proximal to $\mathrm{RFLP}^{\mathrm{B}^{\prime}}$ (see Fig. $1 \mathrm{~B}, \mathrm{C}$ ).

\section{Identification of the capu transcription unit}

The RFLP mapping indicated that the lesion in $c a p u^{E E}$ lies $\sim 3 \mathrm{~kb}$ proximal to $\mathrm{RFLP}^{\mathrm{B}^{\prime}}$. This suggested that at least a portion of the capu transcription unit would lie in 
Figure 1. (A) RFLP mapping of capu. To further localize the capu gene within the cytological region $24 \mathrm{C} 3,4-24 \mathrm{D} 3,4$, we mapped capu with respect to a $\mathrm{P}\left[\mathrm{w}^{+}\right]$element that was inserted in 24D1,2 (see text). $(B, C)$ The capu region proximal to the $\mathrm{P}\left[W^{+}\right]$element. $(B)$ To locate the capu gene within the $100-\mathrm{kb}$ chromosomal walk shown in $C, \mathrm{P}\left[\mathrm{w}^{+}\right]$-capu recombinant chromosomes were analyzed for RFLPs found within the walk (see text). (C) Molecular map of the chromosomal walk through the capu region. The restriction map shows EcoRI sites throughout the region. The arrow above the restriction map represents the capu transcription unit. (RFLP) Molecular positions of the RFLPs discussed above. The position of the $1-\mathrm{kb}$ insertion in $\mathrm{capu}^{7 L}$ is shown on the map $(\nabla)$. Steps of the walk are shown below the restriction map. Clone M6 is a phage clone generously provided by Tulle Hazelrigg. Clones AZ1M-6A, AZ2M-5A, AZ3M-6A, AZ4M-2A, AZ5M-2A, and AZ6M-6A are phage clones and AZC5-2 is a cosmid clone.

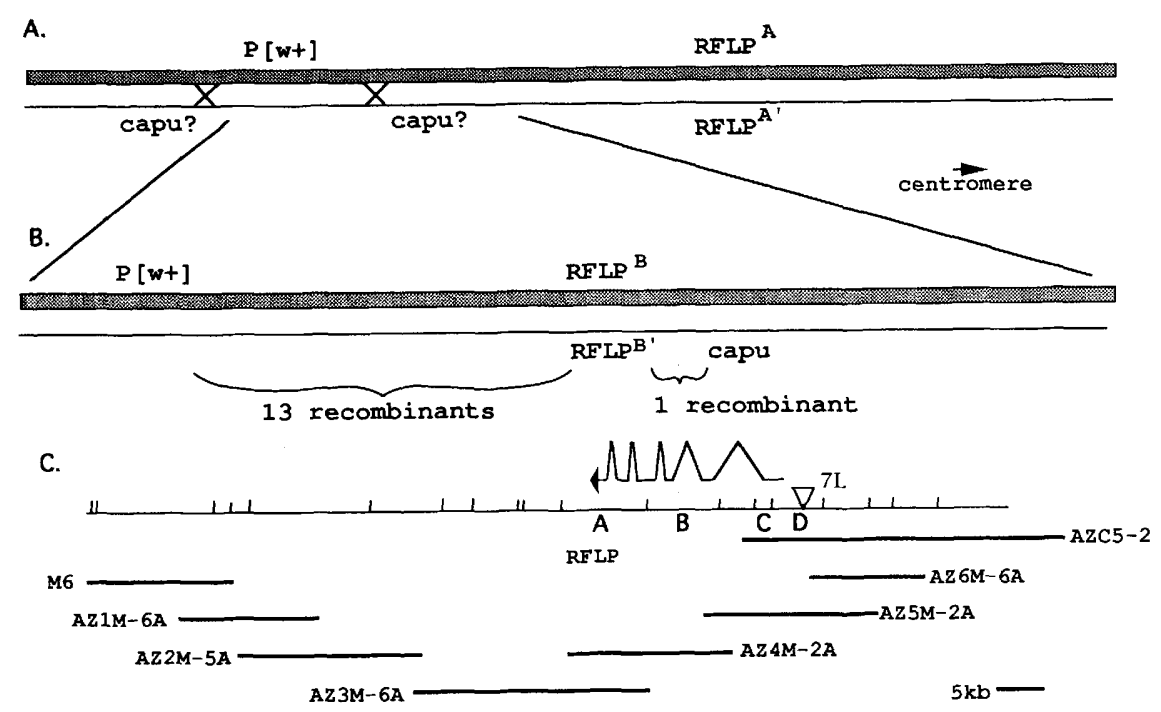

clone AZ4M-2A (see Fig. 1C). To identify potential capu transcription units, we probed Southern blots containing steps of the chromosomal walk extending $\sim 23 \mathrm{~kb}$ proximal (AZ4M-2A and AZ5M-2A) and $12 \mathrm{~kb}$ distal (AZ3M6A) to RFLP $^{\mathrm{B}^{\prime}}$ with digoxygenin (DIG)-labeled cDNA probe made from poly $(\mathrm{A})^{+}$ovary RNA. This analysis revealed that restriction fragments A, B, C, and D in Figure $1 \mathrm{C}$ were the only regions transcribed in ovaries in a 35 $\mathrm{kb}$ region surrounding the location pinpointed as containing capu by the RFLP analysis. The signal in the capu region was approximately half that seen for the positive control $f_{s}(1) K 10$ (Haenlin et al. 1987). Subsequent isolation and analysis of cDNAs from these regions revealed that these four transcribed fragments represent a single, $4.0-\mathrm{kb}$ ovarian transcription unit. Thus, in a $35-\mathrm{kb}$ region extending $23 \mathrm{~kb}$ proximal and $12 \mathrm{~kb}$ distal to the region pinpointed by the RFLP analysis as containing capu, there is only a single ovarian transcription unit. A $4.0-\mathrm{kb}$ transcript was identified by Northern analysis of wild-type ovarian poly $(\mathrm{A})^{+}$mRNA using nonrepetitive regions of this cDNA as probe. Southern blot analysis of genomic DNA from mutant alleles indicates that a weak EMS-induced allele, $\mathrm{capu}^{7 L}$, contains a $1-\mathrm{kb}$ insertion within $3.5 \mathrm{~kb}$ of the $5^{\prime}$ end of this transcription unit (see Fig. 1C) when compared with the parent chromosome, providing further evidence that this is the capu transcript.

In summary, RFLP analysis pinpointed the location of capu to $3 \mathrm{~kb}$ proximal to $\mathrm{RFLP}^{\mathrm{B}^{\prime}}$. In this exact location, we have identified a transcription unit that is expressed in ovaries. This is the only ovarian transcription unit in a 35-kb region surrounding the point suggested to contain capu by the RFLP analysis. A weak EMS-induced allele contains an insertion within $3.5 \mathrm{~kb}$ of the begin- ning of the transcription unit. DNA sequencing of mutant alleles confirmed that this transcription unit encodes capu (see below).

capu $m R N A$ is present in the germ line and soma during oogenesis and is expressed throughout development

We examined the expression pattern of the capu transcription unit during oogenesis with in situ hybridization of DIG-labeled RNA probes made from the capu cDNA clone (see Fig. 2). The earliest accumulated mRNA is in region 2 of the germarium. The mRNA is present in the nurse cells of stage 1-13 egg chambers. In stages 4-9, we also see staining of the oocyte nucleus. In addition, there is a low level of staining in the follicle cells, first evident by stage 4 and continuing through stage 11. This mRNA distribution is consistent with the earliest known phenotype for capu, the lack of posterior localization of staufen protein at stage 8 of oogenesis (St. Johnston et al. 1991) and with the germ-line requirement for capu identified in mosaics (Manseau and Schüpbach $1989 \mathrm{~b}$ ). There is no phenotype known to result from lack of expression of capu in the follicle cells of the egg chamber.

We also examined the distribution of the capu mRNA during other stages of development using Northern analysis (see Fig. 3). The 4.0-kb message is present throughout embryogenesis but is absent by the first larval instar. It reappears during the third larval instar and is present in ovarectamized females and in adult males. A slightly larger transcript of $\sim 4.3 \mathrm{~kb}$ is also present in these later stages of development. There is no known phenotype for capu corresponding to the expression outside of the ovary in females or to the expression in adult males. 


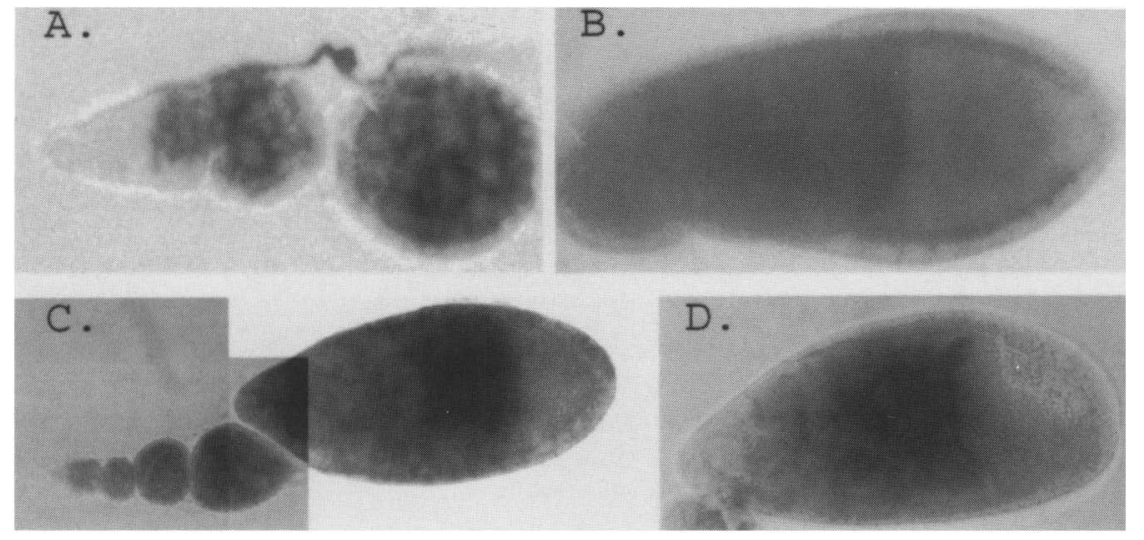

Figure 2. Distribution of the capu transcript in ovaries. Tissue in situ hybridizations were performed as described (Tautz and Pfeifle 1989) with a nonrepetitive probe made from a $1-\mathrm{kb}$ EcoRI-NotI fragment at the $3^{\prime}$ end $(A, B)$, and a $0.9-\mathrm{kb}$ EcoRI fragment at the $5^{\prime}$ end of the cDNA $(C, D)$. Similar staining patterns were observed for each probe. $(A)$ Expression in the germarium beginning in region 2. $(B)$ Expression in the follicle and nurse cells of a stage 10 egg chamber. Note the basal position of expression in the follicle cells. $(C)$ mRNA staining pattern from germarium through stage 8 egg chambers. $(D)$ Stage 9 egg chamber showing staining of oocyte nucleus. capu is highly related to the vertebrate limb deformity locus and shares small domains of similarity with a number of other proteins

DNA sequencing of the capu cDNA clone revealed the presence of a 1058-amino-acid open reading frame (ORF) that is predicted to encode a $114-\mathrm{kD}$ protein (see Fig. 4A). Comparison of the DNA sequence of the capu cDNA clone with sequences in GenBank by use of BLASTX (Altschul et al. 1990) indicated a striking similarity between the carboxy-terminal 503 amino acids of capu and the formins, encoded by the ld locus of mouse and chicken (Woychil et al. 1990; Jackson-Grusby et al. 1992; Trumpp et al. 1992). By use of an alignment generated by

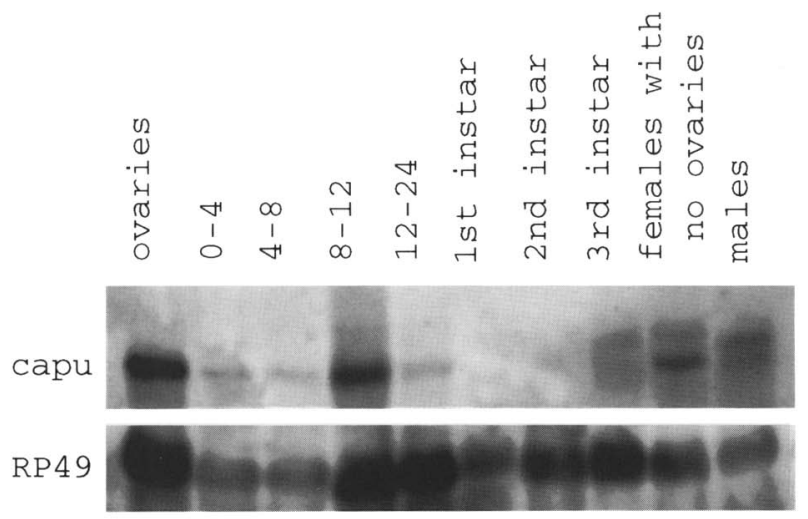

Figure 3. Distribution of the capu transcript during development. Poly $(\mathrm{A}){ }^{+}$mRNA $(5 \mu \mathrm{g})$ from ovaries, $0-4 \mathrm{hr}, 4-8 \mathrm{hr}, 8-12$ $\mathrm{hr}$, and 12-24 hr embryos, first, second, and third larval instars, adult males, and females, from which the ovaries were removed, was electrophoresed, transferred to nylon membrane, and hybridized with a $0.9-\mathrm{kb}$ EcoRI fragment probe from the $5^{\prime}$ end of the $4.3-\mathrm{kb}$ capu cDNA clone $(A)$, and a plasmid containing the ribosomal protein 49 gene $(R P 49)(B)$. The $4.0-\mathrm{kb}$ capu message found in ovaries, throughout embryogenesis and in third larval instars and the 4.3-kb capu message found in adult males and ovarectamized adult females are indicated. The RP49 probe was included to indicate whether equivalent amounts of mRNA were loaded on the gel.
BESTFIT (Devereux et al. 1984), the carboxy-terminal portion of the capu protein is $40 \%$ identical and $60 \%$ similar to the mouse or chicken formins (see Fig. 4C). In addition, there is a 71 -amino-acid region within the carboxy-terminal domain that is highly conserved both with the formins and with a number of other proteins (see Fig. 4B,C), including the Saccharonyces cerevisiae bud neck involvement 1 (BNI1) (J. Pringle, pers. comm.), Aspergillus FigA [forced expression inhibition of growth (Aspergillus)] |Marhoul and Adams 1995), a Drosophila gene known as diaphanous (dia) (Castrillon and Wasserman 1994), two Schizosaccharomyces pombe genes called $C D C 12$ (F. Chang, pers. comm.) and fus 1 (Petersen et al. 1995), a genetically undefined $S$. cerevisiae ORF in GenBank, an Arabidopsis EST, a human EST, and a rice EST. This domain of similarity was independently identified by ourselves and S. Wasserman and has been named the $\mathrm{FH} 2$ domain (Castrillon and Wasserman 1994).

The carboxy-terminal portions of capu and of the vertebrate formins are preceded by a proline rich region of $\sim 162$ amino acids. This proline-rich region (also known as the FH1 domain (Castrillon and Wasserman 1994) is present with approximately the same spacing from the FH2 domain in BNI1, FigA, dia, CDC12, and the yeast ORF (see Fig. 4B). The proline-rich region in mouse formin has been demonstrated to be capable of acting as a binding site for a Src homology 3 (SH3) domain (Ren et al. 1993). Numerous sites within the proline-rich region of capu are candidates for $\mathrm{SH} 3$ domain-binding sites (Ren et al. 1993; Sparks et al. 1994; Yu et al. 1994). On the basis of randomizations with BESTFIT, the amino-terminal 484 amino acids of capu do not appear similar to those of the mouse or chicken formins, nor does there appear to be any significant similarity between capu and $B N I 1, F i g A, C D C 12$, or the yeast ORF outside of the FH2 domain and the proline-rich region. We do, however, find significant similarity between capu and dia in the region between the proline-rich region and the $\mathrm{FH} 2$ domain (see Fig. 4B). Finally, we would like to point out that the formins, BNI1, Figa, CDC12, dia, fus1, and the yeast ORF have regions that are predicted by the algorithm of 
Lupas et al. (1991) to form coiled-coils, but capu does not.

To provide further confirmation that we have identified the capu gene and to identify regions of the protein that are functionally important, we have sequenced the region carboxy-terminal to position $2200 \mid \sim 47 \%$ of the protein coding region) from genomic DNA of the $8 \mathrm{mu}-$ tant alleles $\left(\mathrm{capu}^{G 7}, \mathrm{capu}^{E E}, \mathrm{capu}^{H K}, \mathrm{capu}^{R K}, \mathrm{capu}^{38}\right.$, $\mathrm{capu}^{7 L}, \mathrm{capu}^{2 F}$, and $\mathrm{capu}^{3871}$ ) and compared it to the respective parental chromosomes. $\mathrm{capu}^{R K}, \mathrm{capu}^{2 F}$, and $c a p u^{H K}$ are all missense mutations outside of the FH2 domain, but at positions conserved with the formins (see Fig. $4 \mathrm{~A}, \mathrm{C})$. capu $^{38}$, an extremely weak allele, contains a missense mutation at an amino acid position not conserved with the formins. We have also sequenced across all intervening sequence junctions in this region and in $c a p u^{3871}$ have identified a $23-b p$ deletion 5 bp $5^{\prime}$ of the $3^{\prime}$ acceptor site of the intervening sequence at position 3269. This deletion eliminates the branch site and pyrimidine tract within the intron, suggesting that splicing is unlikely to occur correctly at this site.

\section{capu females produce both dorsalized and ventralized eggs and embryos}

The initial morphological characterization of capu described mutant eggs and embryos as dorsalized and having posterior group defects (Manseau and Schüpbach 1989b). Subsequent analyses of capu (and spir) revealed that the defects in the dorsal-ventral axis are quite variable with ventralized eggs and embryos (Schüpbach 1987) also being produced from females homozygous for certain alleles (see Fig. 5C,F). This suggests that the defect in mutant egg chambers might be a general disruption of the dorsal-ventral pathway

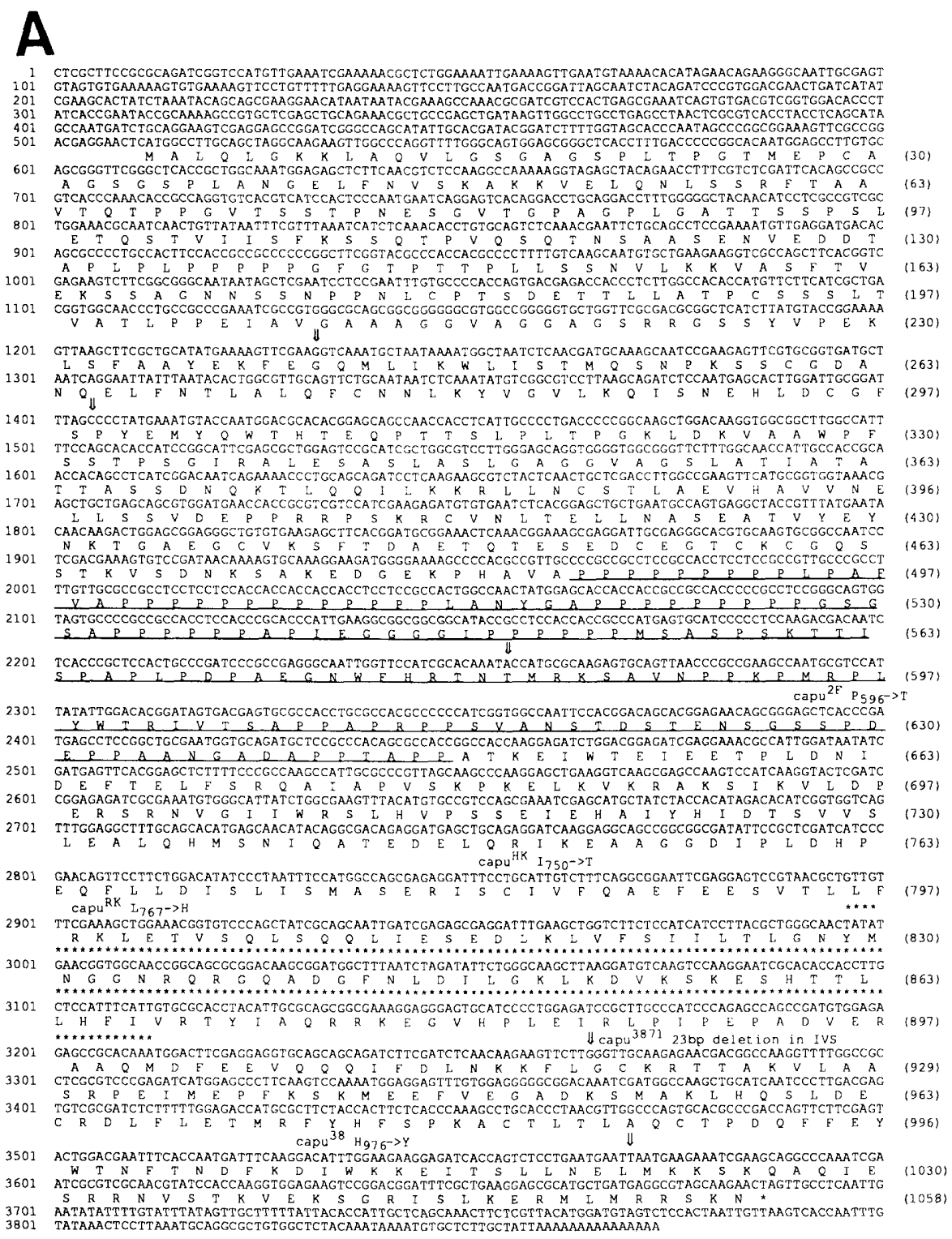

Figure 4. (See facing page for $B, C$, and legend.) 


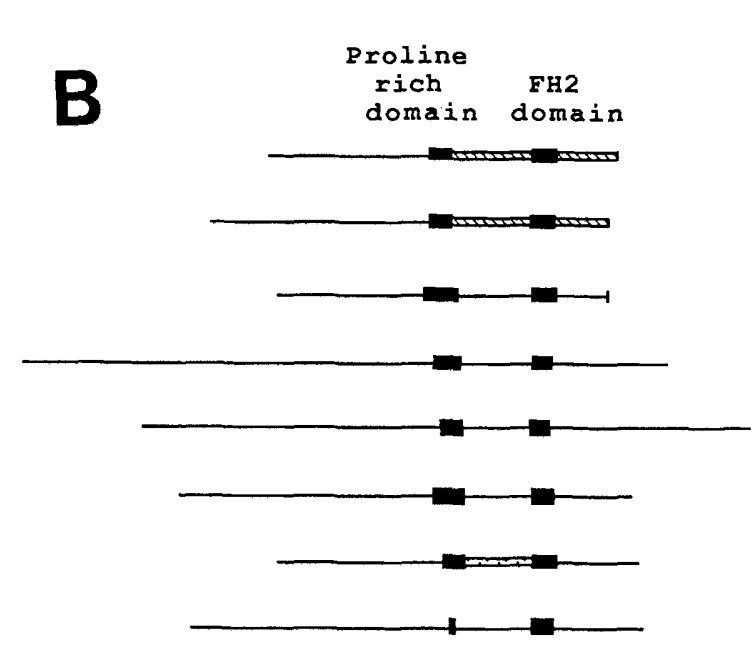

\begin{tabular}{|c|c|c|c|}
\hline & $\begin{array}{r}c \\
8 \\
8 \\
\end{array}$ & $\begin{array}{l}\text { FH2 do } \\
\text { mpared } \\
\text { dentity }\end{array}$ & $\begin{array}{l}\text { omain } \\
\text { with capu } \\
8 \text { Similarity }\end{array}$ \\
\hline capu & & & \\
\hline formin & IV & 50 & 69 \\
\hline FigA & & 38 & 64 \\
\hline BNI 1 & & 38 & 61 \\
\hline $\operatorname{CDC} 12$ & & 35 & 58 \\
\hline yeast & ORF & 33 & 57 \\
\hline dia & & 30 & 58 \\
\hline fus 1 & & 30 & 54 \\
\hline
\end{tabular}

$\underline{\mathrm{C}}$

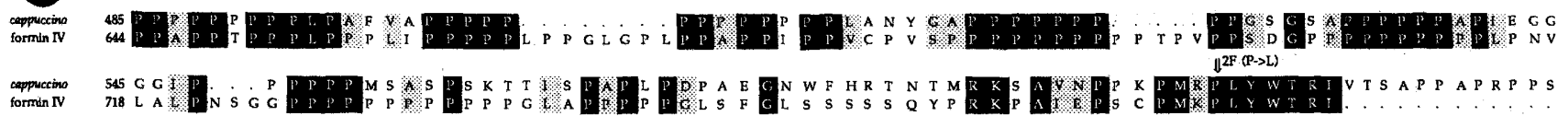

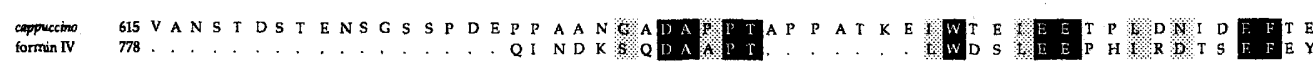

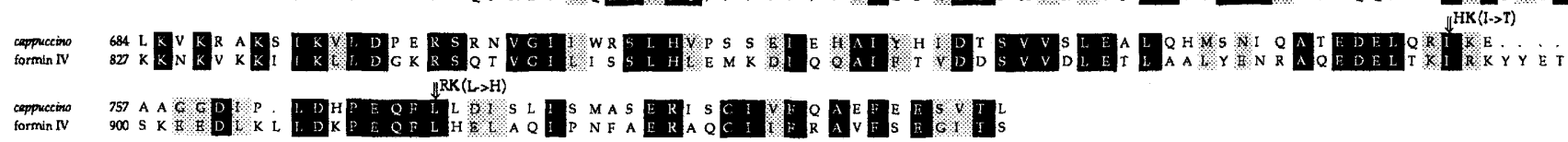

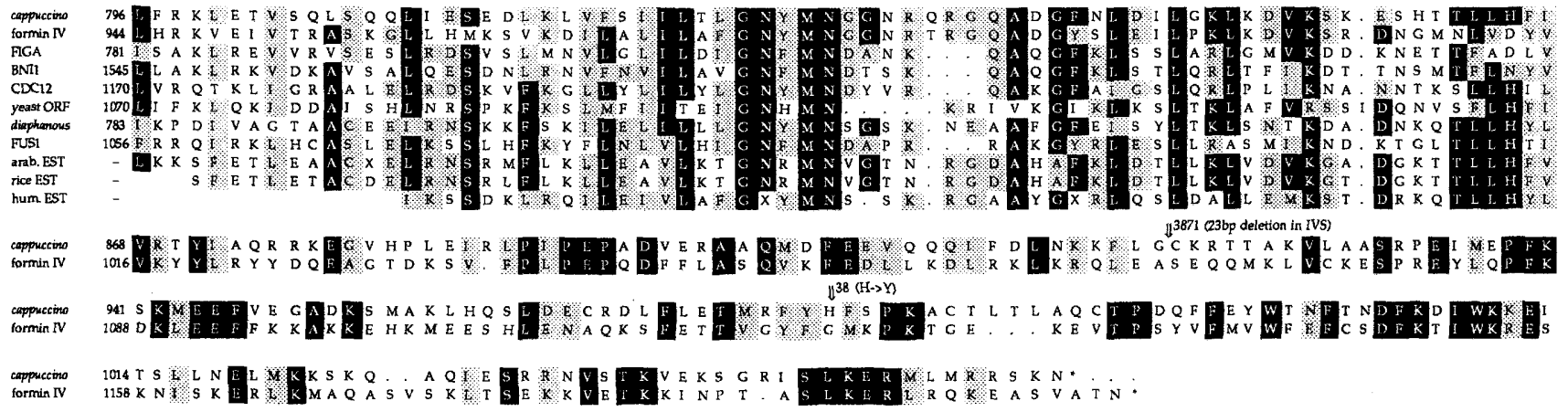

Figure 4. Sequence analysis of capu. (A) Primary sequence of the capu cDNA clone (GenBank accession no. U34258). The predicted 114-kD protein encoded by the 1058-amino-acid ORF is shown below the DNA sequence. The protein consists of 3 domains: the amino-terminal 484 amino acids, which are not conserved; the proline-rich region, which is underlined; and the carboxy-terminal 503 amino acids, which are conserved with the vertebrate $1 d$ proteins (see Fig. $B$ and $C$ ). The asterisks indicate the FH2 domain. DNA and amino acid changes identified in mutant alleles are noted. $(\downarrow)$ Known intervening sequences. All intervening sequences have been identified $3^{\prime}$ to position 2200 by genomic sequencing. Additional intervening sequences may be present $5^{\prime}$ to 2200 . $(B)$ Line drawing showing the conserved spacing between the proline-rich and FH2 domains. The small solid rectangles represent the proline-rich and FH2 domains, whereas the hatched rectangles indicate the region of similarity between capu and the formins and the stippled rectangle indicates the region of similarity between capu and dia (25\% identity, $46 \%$ similarity outside of the FH 2 and proline-rich domains). Only partial sequence for FigA is available. The percent sequence identity and similarity in the FH2 domain between capu and the other FH2 domain containing proteins is indicated. $(C)$ Multiple alignment (GCG Pileup) of the similar domains of capu, mouse formin IV (Jackson-Grusby et al. 1992), Drasophila dia (Castrillon and Wasserman 1994), S. cerevisiae BNI1 (J. Pringle, pers. comm.), S. pombe CDC12 (F. Chang, pers. comm.), Aspergillus FigA (Marhoul and Adams 1995), S. pombe fus1 (GenBank accession no. L37838; Petersen et al. 1995), an unnamed $S$. cerevisiae ORF (GenBank accession no. 238059, NCBI gi:557764), a human EST (GenBank accession no. R39757), a rice EST (GenBank accession no. D24760), and an Arabidopsis EST (GENBANK accession no. R30345). While the entire carboxy-terminal regions of capu and the formins are shown, only the FH2 domains of the other proteins are shown. Amino acid changes found in capu mutant alleles are marked. There is no significant alignment between $S$. cerevisiae BNI1, S. pombe CDC12, $S$. pombe fus1, Aspergillus FigA, the human EST, the Arabidopsis EST, the rice EST, and the unnamed $S$. cerevisiae ORF in the carboxyl domain outside of the proline-rich and $\mathrm{FH} 2$ regions. We do, however, see a significant alignment between the formins and dia in the carboxyl domain outside of the proline-rich and $\mathrm{FH} 2$ regions, but the similarity is substantially lower $141 \%$ identity, $60 \%$ similarity between capu and formin IV vs. $20 \%$ identity, $45 \%$ similarity between dia and formin IV). Where a majority of the sequences are identical, they are shaded in black. Where a majority are similar to each other, they are shaded in gray. Similar is defined as a similarity $>0.5$ in the normalized Dayhoff matrix used by UWGCG (Gribskov and Burgess 1986). 
rather than loss of a specific component of the pathway.

capu egg chambers display abnormal microtubule distributions and premature cytoplasmic streaming

Because capu (and spir) affect both the dorsal-ventral and anterior-posterior axes, we suggested that the mutants might affect the cytoskeleton (Manseau and Schüpbach 1989 b). To examine the microtubule cytoskeleton, mutant and wild-type ovaries were labeled by indirect immunofluorescence with an antibody directed against $\alpha$-tubulin. Abnormal microtubule distributions were seen in mutant stage 8 and 9 egg chambers (see Fig. 6). Long and thick immunofluorescently labeled tubulin fibers are seen wrapping around the cortex of mutant oocytes that are not seen in similarly staged wild-type oocytes (see also Theurkauf 1994).

This phenotype is reminiscent of that seen in yeast when $\alpha$ - and $\beta$-tubulin are overexpressed-unusual structures containing microtubules are seen around the cortex of the cell (Burke et al. 1989; Bollag et al. 1990). It is difficult to assess the levels of tubulin in mutant and wild-type egg chambers because the configuration of the microtubules is different in these two genotypes. For this reason, we examined the tubulin levels in mutant and wild-type egg chambers by use of immunoblots. Both $\alpha$ and $\beta$-tubulin are found in equivalent levels in mutant and wild-type egg chambers (data not shown), suggesting that the reason for the novel microtubule distribution is

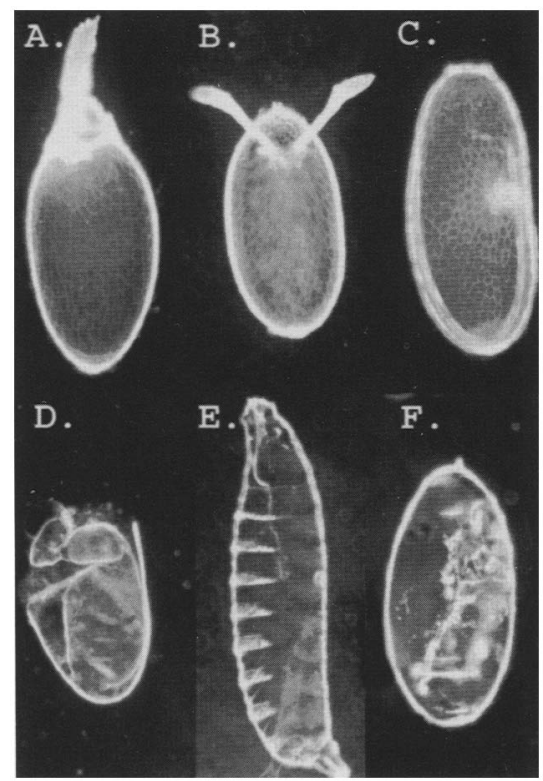

Figure 5. Dorsal-ventral defects in capu eggs and embryos. $(A)$ Dorsalized eggshell from a $c a p u^{E E}$ homozygous female; $(B)$ a wild-type eggshell; $|C|$ ventralized capu eggshell from capu ${ }^{G 7}$ homozygous female; $(D)$ dorsalized capu embryo from a $c a p u^{E E}$ homozygous female; $(E)$ a wild-type embryo removed from the vitelline membrane; $(F)$ ventralized capu embryo from capu ${ }^{G 7}$ homozygous female.

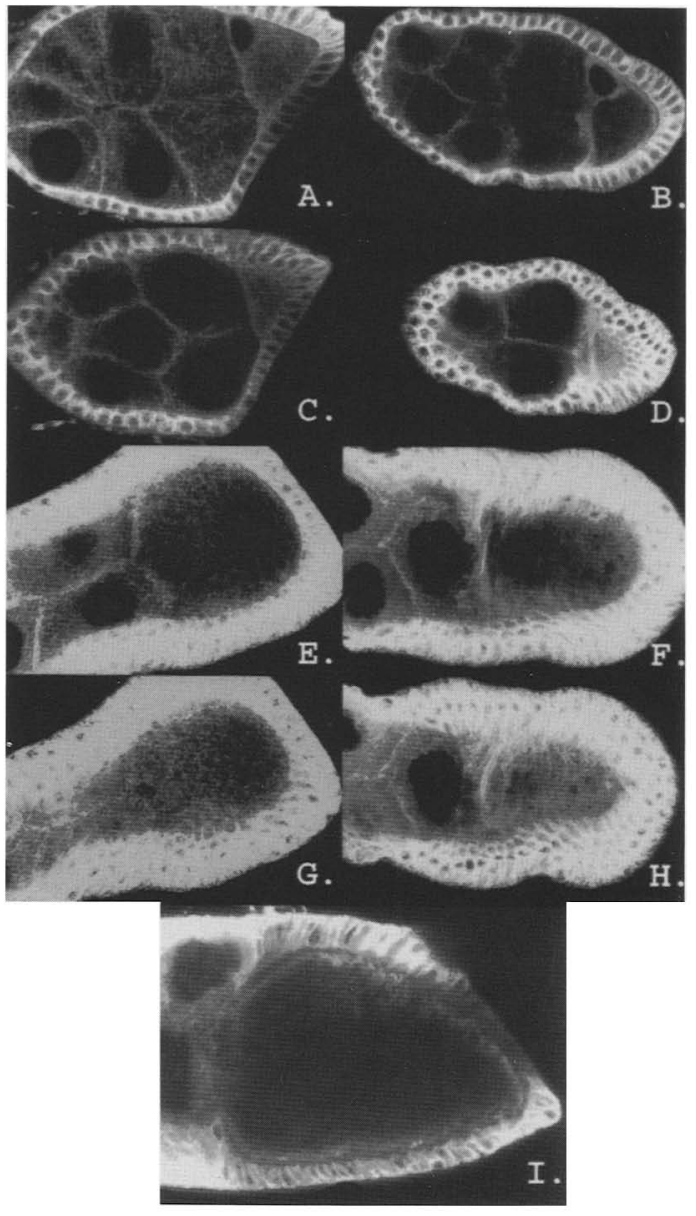

Figure 6. Microtubule distribution in wild-type and capu mutant oocytes. Stage $8(A-D)$, stage $9(E-H)$, and stage $10(I)$ egg chambers stained with Drosophila anti- $\alpha$-tubulin. $A, C, E, G$, and $I$ are from wild-type egg chambers; $B, D, F$, and $H$ are from $\mathrm{capu}^{E E} / \mathrm{capu}^{E E}$ egg chambers. The sections in $A, B, E$, and $F$ are from central regions of the egg chamber; those in $C, D, G, H$, and $I$ are from near the cortex.

not high levels of tubulin in mutant egg chambers. The possibility still exists, however, that tubulin levels are normal within the egg chamber as a whole, but are elevated within the oocyte.

Because the abnormal distribution of microtubules in mutant stage 8 egg chambers resembles that seen in stage 10 wild-type oocytes, Theurkauf examined the behavior of capu mutant egg chambers and found that they undergo premature cytoplasmic streaming within the oocyte (W.E. Theurkauf, pers. comm.). We have confirmed this finding and have also seen this phenotype in spir mutant egg chambers. The premature streaming within the oocyte is inhibitable by colchicine, indicating that it, like that at stage 10 in wild-type oocytes, is microtubule based.

To determine whether the premature streaming is likely to be the cause of the patterning defects in capu, we have carefully analyzed the speed and timing of streaming in a capu mutant allelic series. We see no significant difference in the speed of streaming between 
weak $\left(\mathrm{capu}^{2 F},<5 \%\right.$ abnormal eggshells), moderate (capu $^{R K}, 40 \%-70 \%$ abnormal eggshells), and strong alleles $\left\langle\right.$ capu $^{G 7},>75 \%$ abnormal eggshells; capu $^{E E}, 60 \%-$ $90 \%$ abnormal eggshells) at stage 8 of oogenesis (see Fig. 7). Nor do we see a difference in the speed of streaming between a strong allele that dorsalizes, $c a p u^{E E}$, and a strong allele that weakly ventralizes, $c a p u^{G 7}$. Thus, the speed of streaming does not correlate with the strength of the mutant allele (as shown by the percentage of eggshells exhibiting dorsal-ventral defects). The dorsalventral defects in capu mutant offspring are thought to result from the mislocalization of gurken mRNA at stage 9 of oogenesis. Therefore, we measured the speed of

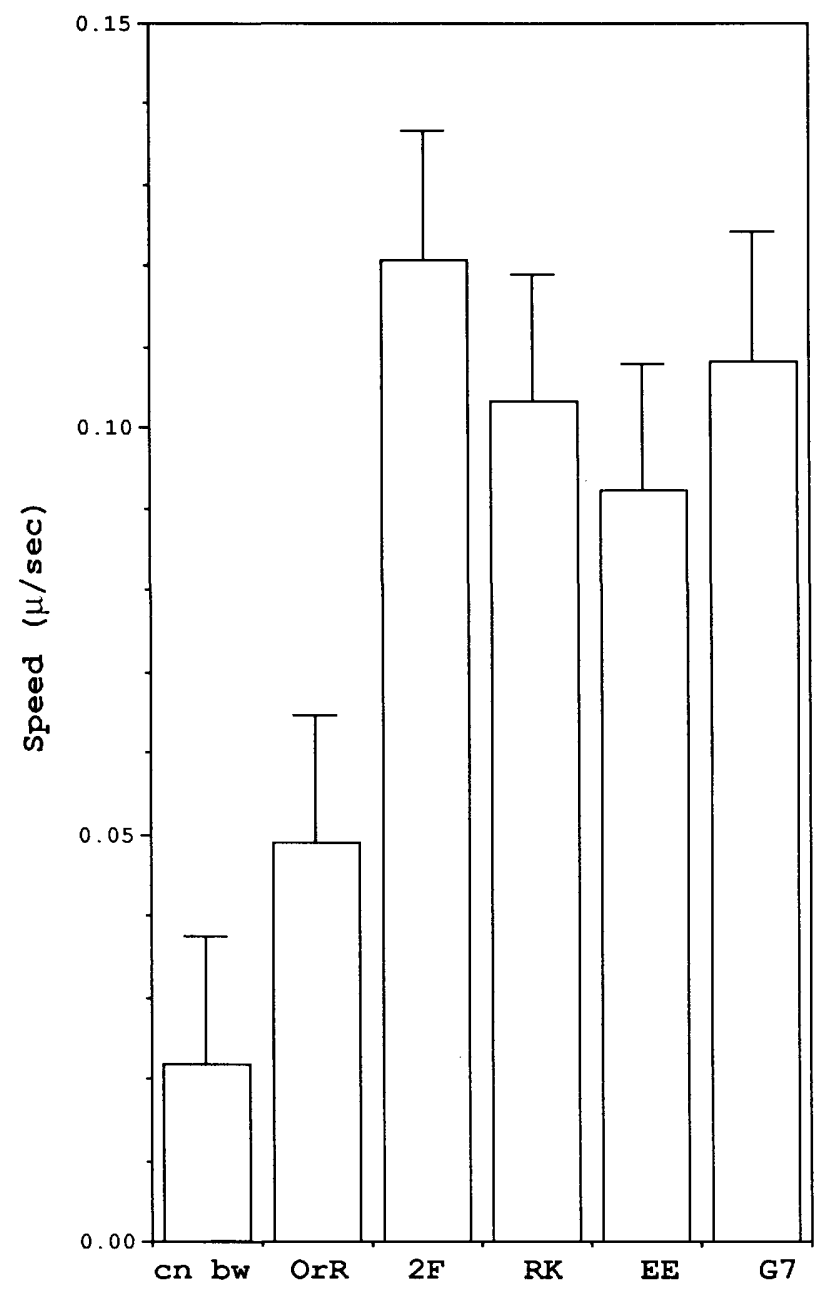

Figure 7. Speed of cytoplasmic streaming in wild-type and capu mutant oocytes. The speed of streaming at stage 8 of oogenesis is shown for two wild-type strains: (cn bw) cn bw/cn $b w, \mathbf{n}=12$ and (OrR) Oregon $\mathbf{R}, \mathbf{n}=13$; for capu mutant alleles: strong alleles: (G7) $\mathrm{capu}^{G 7} / \mathrm{capu}^{G 7}, \mathrm{n}=9$ and (EE) $\mathrm{capu}^{E E} /$ $\mathrm{capu}^{E E}, \mathrm{n}=9$; moderate alleles (RK) $c a p u^{R K} / \mathrm{capu}^{R K}, \mathrm{n}=10$; and weak alleles $(2 \mathrm{~F}) \mathrm{capu}^{2 F} / \mathrm{capu}^{2 F}, \mathrm{n}=11$. By Tukey's test of multiple comparisons (SAS Proc GLM) the speeds of streaming in the capu mutant genotypes are indistinguishable from each other and are distinguishable from the parental strain $c n$ bw at the 0.05 level. All are also distinguishable from the wild-type strain Oregon $\mathrm{R}$ except for $c a p u^{E E}$. Oregon $\mathrm{R}$ and $c n$ bw are not distinguishable from each other. The error bars represent the s.E. streaming in stage 9 oocytes of the weak allele capu ${ }^{2 F}$, an allele that has a normal dorsal-ventral axis. We do not see a decline in the speed of streaming at stage 9 in the weak allele $c a p u^{2 F}$. Thus, neither the speed nor the timing of streaming can account for the difference between weak and strong capu dorsal-ventral phenotypes.

\section{Premature ooplasmic streaming displaces posterior but not dorsal-ventral determinants}

Two distinct models can be invoked to explain the lack of properly localized molecular determinants in capu and spir. The first is that after determinants are localized to their proper intracellular position during stages 8 and 9 of oogenesis, they must be anchored to the cytoskeleton to be stable to the cytoplasmic streaming that happens during stage 10 . In this model, the premature cytoplasmic streaming during stages 8 and 9 in capu and spir mutant oocytes happens before this anchoring step and thus sweeps away molecular determinants. In the second model, it is the misorganization of the microtubules, required for subcellular targeting of determinants, that is responsible for the localization defects. Cytochalasin D treatment induces premature, microtubule-dependent cytoplasmic streaming within the oocyte of approximately the same speed as that seen in capu $(0.1 \mu \mathrm{m} / \mathrm{sec})$. This induced streaming is accompanied by microtubule bundling around the cortex of the oocyte (J. Calley, $\mathrm{H}$. Phan, S. Emmons, and L. Manseau, in prep). This ability to induce cytoplasmic streaming provided us with a unique opportunity to distinguish between these models.

To determine whether streaming induced with cytochalasin $\mathrm{D}$ results in the mislocalization of molecular determinants similar to what is seen in capu and spir, we examined the distribution of determinants in egg chambers that were treated with cytochalasin D for 15 or 30 min and then fixed. Staufen protein is one of the earliest components to localize to the posterior pole in wild-type oocytes, but does not localize to the posterior pole in capu, and spir mutant oocytes (St. Johnston et al. 1991). In the dorsal-ventral axis, gurken mRNA is localized in wild-type oocytes specifically to the dorsal-anterior corner near the oocyte nucleus in stage 8 egg chambers, whereas in capu and spir mutant oocytes, gurken mRNA is found along the entire anterior end of the oocyte (Neuman-Silberberg and Schüpbach 1993). We induced streaming in wild-type egg chambers by immersing ovaries in cytochalasin $\mathrm{D}$, then examined the distribution of staufen protein and gurken mRNA during stages 8 and 9 . We found that after $15 \mathrm{~min}$ of ooplasmic streaming induced by cytochalasin $\mathrm{D}$, the amount of staufen staining at the posterior pole is only slightly reduced. After 30 min of cytoplasmic streaming, however, there is virtually no localized staufen staining at the posterior pole (see Fig. 8). In contrast, even in stage 8 oocytes that have been streaming for $30 \mathrm{~min}$, gurken mRNA is found tightly localized at the oocyte nucleus (see Fig. 8). Thus, the posterior localization of staufen protein is not stable to cytoplasmic streaming at stage 8 of oogenesis, but the localization of gurken mRNA to the oocyte nucleus is. 

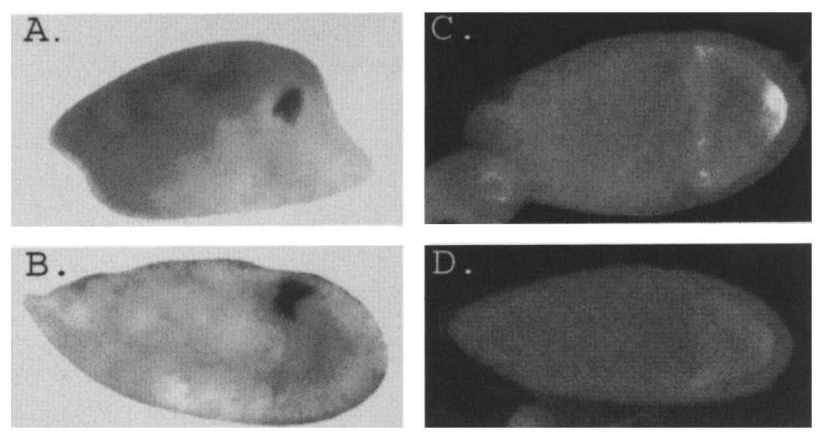

Figure 8. Distribution of determinants after $30 \mathrm{~min}$ of cytoplasmic streaming. $(A, B)$ The distribution of gurken mRNA in stage 8 oocytes of untreated wild-type oocytes $(A)$, and wild-type oocytes treated with cytochalasin D for $30 \mathrm{~min}(B)$. After $30 \mathrm{~min}$ of cytoplasmic streaming, the gurken mRNA staining is indistinguishable from wild type. $(C, D)$ The distribution of staufen protein in stage 8 oocytes of untreated wild type $(C)$ and wildtype treated with cytochalasin $\mathrm{D}$ for $30 \mathrm{~min}(D)$. After $30 \mathrm{~min}$ of cytoplasmic streaming, the staufen protein no longer localized to the posterior pole.

\section{Discussion}

capu is highly related to the vertebrate formins

capu is most closely related to the products of the $1 d$ locus, known as the formins, being $40 \%$ identical and $60 \%$ similar over the 503 -amino-acid carboxyl terminus of the protein. The amino terminus of the capu protein does not appear to be related to that of the formins. This is not surprising, as the formins have strongly divergent amino termini encoded by a group of alternatively spliced messages. In particular, one splice product of the mouse $1 d$ locus, formin IV, produces a protein with an acidic amino terminus $(\mathrm{pI}=4.5)$, whereas the $\mathrm{pI}$ of the amino termini of the other three isoforms is basic $(\mathrm{pI}=9.8)$ (Jackson-Grusby et al. 1992). The amino terminus of capu most closely resembles that of formin IV in this respect, having a $\mathrm{pI}$ of 5.27 . The variation in the amino terminus of this gene family suggests that the amino- and carboxy-terminal regions of the protein are probably separate functional domains with perhaps only the carboxy-terminal function being conserved between capu and the vertebrate formins.

The $1 d$ locus, like capu, functions in polarity. Mutants in the mouse $1 d$ locus have truncations of the anteriorposterior limb axis resulting in fusions of digits, indicating that the gene functions in limb patterning (Zeller et al. 1989). The morphology and packing of the cells of the apical ectodermal ridge (AER) is abnormal in ld mutant animals, suggesting that the AER is defective either in differentiation or in organization (Zeller et al. 1989). The ld locus is expressed at a fivefold higher level in the ectoderm than in the neighboring mesenchyme. Taken together with the fact that the anterior-posterior axis defects in $1 d$ are similar to those seen when portions of the AER are removed, this suggests that the AER is the primary focus of the defects in $1 d$ anterior-posterior axis formation (Zeller et al. 1989). In addition to limb defects, ld mutants often exhibit renal aplasia (Trumpp et al. 1992).

Chick formin has been shown to be localized in a punctate pattern in the nucleus and to be distributed throughout the cytoplasm during mitosis (Trumpp et al. 1992). The nuclear localization of the chick formin (Trumpp et al. 1992) and the binding of mouse formin IV to DNA-cellulose in crude nuclear extracts (Vogt et al. 1993) has led to the suggestion that the protein might function as a transcription factor, although the lack of in vivo localization to the chromosomes (Trumpp et al. 1992/ casts doubt on this hypothesis. A second possible nuclear function-in splicing-has been partially discredited because the protein does not colocalize with at least some spliceosomes (Trumpp et al. 1992).

The in vitro demonstration of an $\mathrm{SH} 3$ domain-binding region in mouse formin suggests a role for the formins in protein-protein interactions during signal transduction or in the cytoskeleton (Gout et al. 1993; Mayer and Baltimore 1994; see references in Musacchio et al. 1992; Pawson and Gish 1992). The exact function of SH3 domain-ligand interaction is not well-defined. In a number of enzymes, the $\mathrm{SH} 3$ domains play a role in regulation of enzymatic activity (Gout et al. 1993; Mayer and Blatimore 1994; Pleiman et al. 1994). They are also thought to provide specificity to protein-protein interactions (Gout et al. 1993; Ren et al. 1993; Lim et al. 1994). In at least some cases, the $\mathrm{SH} 3$ domain can target molecules to a particular subcellular location. For instance, the $\mathrm{SH} 3$ domain of phospholipase $\mathrm{C} \gamma$ is sufficient for targeting to stress fibers, whereas that of GRB2 targets to membrane ruffles (Bar-Sagi et al. 1993).

\section{The FH2 domain containing family}

All of the $\mathrm{FH} 2$ domain-containing proteins for which we have sufficient sequence, also contain a proline-rich region. In addition to capu and the formins, two of these also appear to function in polarity. The $S$. cerevisiae gene $B N I 1$ was identified by mutants that are synthetically lethal with mutants in $C D C 12$, one of the bud neck filament proteins (J. Pringle, pers. comm.). Mutants in $B N I 1$ result in random bud-site selection in diploids during bipolar budding, suggesting a role in cell polarity in yeast. Mutants in Aspergillus FigA result in fat, highly branched hyphae and abnormal hyphal tips (Marhoul and Adams 1995).

Two members of this group play a role in cytokinesis. Mutants in diaphanous (dia) have binucleate cells indicative of defects in cytokinesis during spermatogenesis, during oogenesis in the follicle cells, during imaginal disc development, and in neuroblasts from the larval central nervous system /Castrillon and Wasserman 1994). Mutants in the S. pombe gene CDC12 do not undergo cytokinesis and fail to form the actin contractile ring (F. Chang, pers. comm.). The final gene, S. pombe fus1, functions in conjugation-conjugation tubes meet, but the intervening cell walls do not dissolve (Bresch et al. 1968). 
It is intriguing that all of the proteins identified as containing the $\mathrm{FH} 2$ domain also contain a proline-rich domain with approximately the same spacing. This suggests that these two domains function together in some way. Because the proline-rich region of the formins has been demonstrated to be capable of acting as a binding site for SH3 domains in vitro (Ren et al. 1993), it seems likely that the proline-rich regions in the remaining $\mathrm{FH} 2$ domain-containing proteins are acting similarly. In most of the $\mathrm{FH} 2$ domain-containing proteins, the proline-rich region is quite extensive, being much larger than that required to function in $\mathrm{SH} 3$ domain binding in vitro (Ren et al. 1993; Sparks et al. 1994; Yu et al. 1994). Perhaps these extensive proline-rich regions are serving some additional purpose besides SH3 binding. Proline-rich regions are known to sometimes function as hinge regions between protein domains as has been seen in vinculin (Coutu and Craig 1988). In addition, profilin is known to bind to poly-proline in vitro (Tanaka and Shibata 1985), although the significance of this is unclear.

\section{The relationship between microtubule distribution, cytoplasmic streaming, and patterning}

It seems unlikely that the premature cytoplasmic streaming in capu is sufficient to explain all of the patterning defects. We have extended the observations of Theurkauf (1994) by analyzing streaming in weak, moderate, and strong alleles of capu and see no correlation between the speed or the timing of streaming and the strength of the mutant capu allele. The dorsal-ventral defects in capu are easier to score than the anteriorposterior ones and thus, have been used to rank the mutant alleles (Manseau and Schüpbach 1989; L. Manseau and J. Calley, unpubl.). Thus, the lack of correlation between the dorsal-ventral defects of the mutant alleles and the speed or timing of streaming cannot be explained and suggests that the premature streaming is not the cause of these patterning defects. The same may be true of the posterior defects, but measurement difficulties make this less clear.

That the induction of streaming with cytochalasin $\mathrm{D}$ does not displace gurken mRNA from the oocyte nucleus, indicates that as soon as gurken mRNA is positioned during stages 8 and 9 of oogenesis, it is stable to cytoplasmic streaming. This suggests that the lack of localization of gurken mRNA in capu and spir mutant oocytes is not likely to result from being swept away by premature cytoplasmic streaming. An alternative explanation is that mislocalization results from the microtubules being bundled at the cortex of the oocyte so that they are unable to transport gurken mRNA to its normal intracellular location. As it is currently unknown whether microtubules are required for the localization of gurken mRNA, some other transport system responsible for gurken mRNA localization to the oocyte nucleus may also be disrupted.

In the anterior-posterior axis, the lack of pole cells in capu is completely penetrant, but the extent of abdominal segmentation defects appears to correlate with the strength of the mutant allele (Manseau and Schüpbach $1989 \mathrm{~b})$. This, together with our findings that there is no correlation between the streaming and the strength of the mutant allele, suggests that premature streaming in capu may not explain the posterior defects. It would be easy to miss subtle differences in the speed of streaming between alleles, however, and there are difficulties in quantitating the extent of the posterior defects /which are masked by the dorsal-ventral defects). In addition, the finding that cytochalasin-induced streaming does displace staufen protein from the posterior pole supports the model that premature streaming in capu does result in posterior defects. Pokrywka and Stephenson (1995) report that cytochalasin D treatment does not affect oskar mRNA localization at the posterior pole. We do not believe, however, that these results conflict with ours because the concentration of cytochalasin D used in their study does not induce premature cytoplasmic streaming (L. Manseau, unpubl.).

The observation that capu egg chambers have abnormal distributions of microtubules and premature microtubule-based cytoplasmic streaming suggests it is likely that capu is either directly or indirectly regulating the cytoskeleton. Continued molecular analysis of capu, including protein localization within the oocyte-nurse cell complex should provide clues to the role that this gene family plays in pattern formation. In addition, ongoing molecular analysis of spir, a gene with the same phenotype as capu, should provide further insight into the role capu and related genes play in polarity establishment.

\section{Materials and methods}

RFLP mapping of capu

Females homozygous for $\mathrm{w}$ and for a $\mathrm{w}^{+}$-carrying $\mathrm{P}$ element in 24D1,2 were mated to $w / Y c a p u^{E E} / S M 6, b$ Roi males. In the $F_{1}$, females carrying the $\mathrm{P}\left[\mathrm{w}^{+}\right]$and $c a p u^{E E}$ were mated with $w / Y$ $\mathrm{capu}^{\mathrm{EE}} / S M 6, b$ Roi males. In the $\mathrm{F}_{2}, \mathrm{P}\left[w^{+}\right]$females who had mated with their brothers were placed in groups of 50 into plastic cups and their eggs collected on apple juice agar plates. To identify females carrying $\mathrm{P}\left[\mathrm{w}^{+}\right]-$capu recombinant chromosomes, the plates were examined for the presence of eggs with the capu phenotype. Once such eggs were identified, the females were segregated and their eggs examined to identify the individual $\mathrm{P}\left[\mathrm{W}^{+}\right]$-capu recombinant female. We screened 23,000 chromosomes for recombination events between the $\mathrm{P}\left[\mathrm{W}^{+}\right]$and a mutant capu allele, $\mathrm{capu}^{E E}$, and identified $17 \mathrm{fe}-$ males carrying $\mathrm{P}\left[\mathrm{w}^{+}\right]$-capu recombinant chromosomes. Southern blots of genomic DNA isolated from single recombinant flies (Jowett 1986) were analyzed with DIG-labeled probes as described in the Genius System User's Guide for Filter Hybridization (Boehringer Mannheim).

\section{Northern blot analysis}

Poly $(\mathrm{A})^{+}$mRNA was isolated according to the procedure of Jowett (1986) and Northern blots were prepared as in Sambrook et al. (1989). Each lane contained $5 \mu \mathrm{g}$ of Poly(A) ${ }^{+}$mRNA. Blots were probed using DIG-labeled probes as described in the Genius System User's Guide for Filter Hybridization (Boehringer Mannheim). The probe for the Northern blot of mutant RNA was made from the 1-kb EcoRI-NotI fragment at the $3^{\prime}$ end of 
the gene. The probe for the developmental Northern was made from the $0.9-\mathrm{kb}$ EcoRI fragment from the extreme $5^{\prime}$ end of the gene.

\section{Whole-mount tissue in situ hybridizations}

Whole-mount tissue in situ hybridizations were performed basically as in Tautz and Pfeifle (1989) with DIG-labeled RNA probes. Probes from both the 0.9-kb EcoRI fragment at the 5' end and the 1-kb EcoRI-NotI fragment at the 3' end of the capu gene were used. The gurken probe was made from cDNA clone 1.7 (Neuman-Silberberg and Schüpbach 1993).

\section{DNA sequencing}

DNA sequencing was done by use of a Sequenase kit (U.S. Biochemical). DNA sequencing of mutant alleles was performed on DNA that was PCR amplified from genomic DNA of homozygous mutant alleles and then treated with shrimp alkaline phosphatase and exonuclease I as in the Sequenase PCR Product Sequencing Kit (U.S. Biochemical). Mutant alleles were sequenced in the region between position 2185 and 3754 in the DNA sequence.

\section{Morphological analyses}

Cuticles and chorions were prepared for analysis as described in Wieschaus and Nüsslein-Volhard (1986).

\section{Immunocytochemistry}

Wild-type and mutant ovaries were dissected in Ephrussi and Beadle's Ringer's solution and fixed for $10 \mathrm{~min}$ with vigorous shaking in a 5:1:5 ratio of heptane, $37 \%$ formaldehyde, PEM $10.1 \mathrm{M}$ PIPES, $1 \mathrm{~mm} \mathrm{MgCl}_{2}, 1 \mathrm{~mm}$ EGTA at $\mathrm{pH}$ 6.9). The aqueous phase was removed and an equal volume of $90 \%$ methanol: $10 \% 500 \mathrm{~mm}$ EGTA was added and shaken for $10 \mathrm{sec}$. The ovaries were then rinsed two times with methanol for $10 \mathrm{~min}$ and then rehydrated through a methanol series $(70 \% \mathrm{MeOH}, 50 \%$ $\mathrm{MeOH}$, and $30 \% \mathrm{MeOH}$ in PBS) for $10 \mathrm{~min}$ each wash and then finally washed in PBS for $10 \mathrm{~min}$. Ovaries were blocked for $2 \mathrm{hr}$ in $0.1 \%$ fish gelatin, $0.8 \% \mathrm{BSA}$, and $0.03 \%$ Tween 20 in PBS. Ovaries were then incubated at $4^{\circ} \mathrm{C}$ for $\sim 48 \mathrm{hr}$ with primary antibody diluted in blocking solution with $0.1 \%$ Triton-X 100 . The anti- $\alpha$-tubulin antibody $\{\alpha 4 \mathrm{a} 1)$ was used at a dilution of $1: 10$. Excess primary antibody was then removed by four 30-min washes with blocking solution at room temperature. The antistaufen antibody (provided by Daniel St. Johnston, Wellcome/CRC Institute, Cambridge, UK) was used at a dilution of $1: 10$. Ovaries were then incubated with cy3 (1:100)-labeled secondary antibody diluted in blocking solution for $18 \mathrm{hr}$ at $4^{\circ} \mathrm{C}$. Excess secondary antibody was removed by three 30 -min washes with blocking solution at room temperature. Ovaries were dissected and mounted in a $0.2 \%$ solution of $n$-propylgallate in glycerol for viewing.

\section{Immunoblots}

To assay the levels of tubulin in mutant versus wild-type egg chambers, 50 stage 8 or 9 egg chambers were hand dissected from $c a p u^{G 7} / \mathrm{capu}^{G 7}, \mathrm{capu}^{E E} / \mathrm{capu}^{E E}$, and wild-type Oregon $\mathbf{R}$ females. The egg chambers were then lysed in protein sample buffer at $95^{\circ} \mathrm{C}$ for $5 \mathrm{~min}$. The samples were split in half and the duplicate samples were loaded on a $10 \%$ polyacrylamide-SDS gel. After electrophoretic separation, one set of lanes was stained with Coomassie Blue to assure that the samples were loaded equivalently. Samples on the other half of the gel were transferred to Immobilon-P membrane (Millipore Corp.) (Towbin et al. 1979/ and then probed with antibody raised against Drosophila $\alpha$-tubulin (4a1). Antibodies were visualized by chemiluminescence with the Renaissance system made by DuPont NEN. The anti- $\alpha$-tubulin antibody was then removed from the membrane by washing in $1 \%$ SDS for $10 \mathrm{~min}$ at $50^{\circ} \mathrm{C}$. The blot was then reprobed for $\beta$-tubulin levels with anti- $\beta$-tubulin antibody (Sigma T 4026) and visualized as above.

\section{Time-lapse video microscopy}

Egg chambers were mounted in Robb's saline solution under a coverslip that was supported by pieces of coverslips. The chambers were viewed on a Zeiss Axioplan microscope and recorded with a Sanyo VCB-3524 CCD camera and a Toshiba KV-6300A time lapse video recorder at the rate of one frame every $4 \mathrm{sec}$. To measure the speed of streaming, this was projected on a screen at 60 frames per second $(240 \times)$. With a Sharp QA-1050 LCD Computer Projection Panel, the image of a moving ball produced by a Macintosh computer program (written by J. Calley; available upon request) was projected onto the same screen. After calibration, the direction and speed of the moving ball was modified until it visually matched the speed of the moving cytoplasm. The speed of the moving ball was then recorded as the streaming speed. To show the effect of a drug on streaming, chambers were filmed for $20-30 \mathrm{~min}$. Then the coverslip was lifted and excess solution was removed. Finally, the drug was added and filming was resumed. Colchicine was initially dissolved in DMSO at $20 \mathrm{mg} / \mathrm{ml}$. It was further diluted before use to $20 \mu \mathrm{g} / \mathrm{ml}$ in Robb's saline solution. Controls were performed by adding Robb's saline solution containing $0.1 \%$ DMSO. Cytochalasin D was dissolved in DMSO at $10 \mathrm{mg} / \mathrm{ml}$ and then diluted to $10 \mu \mathrm{g} / \mathrm{ml}$ in Robb's saline solution before use.

\section{Acknowledgments}

We thank T. Hazelrigg for providing DNA flanking the $\mathrm{P}\left[\mathrm{W}^{+}\right]$, Daniel St. Johnston for providing the anti-staufen antibody, and Trudi Schüpbach for providing the gurken cDNA. We thank P. Jansma and S. Selleck for their assistance with confocal microscopy, T. Radabaugh for conducting some genomic Southern analysis, and C. Calley for assistance with the statistical analysis. We thank T. Adams, P. Leder, J. Pringle, W. Theurkauf, T. Vogt, and S. Wasserman for communication of results prior to publication and for helpful discussions. We are also grateful to the other members of the Manseau laboratory and members of the Brower, Selleck, and Ward laboratories for their assistance throughout the progress of this work.

The publication costs of this article were defrayed in part by payment of page charges. This article must therefore be hereby marked "advertisement" in accordance with 18 USC section 1734 solely to indicate this fact.

\section{References}

Altschul, S.F., W. Gish, W. Miller, E. Myers, and D. Lipman. 1990. Basic local alignment search tool. I. Mol. Biol. 215: 403-410. 
Bardsley, A., K. McDonald, and R.E. Boswell. 1993. Distribution of tudor protein in the Drosophila embryo suggests separation of functions based on site of localization. Development 119: 207-219.

Bar-Sagi, D., D. Rotlin, A. Batzer, V. Mandiyan, and J. Schlessinger. 1993. SH3 domains direct cellular localization of signaling molecules. Cell 74: 83-91.

Berleth, T., M. Burri, G. Thoma, D. Bopp, S. Richstein, G. Frigerio, M. Noll, and C. Nüsslein-Volhard. 1988. The role of localization of bicoid RNA in organizing the anterior pattern of the Drosophila embryo. EMBO J. 7: 1749-1756.

Bollag, D.M., I. Tornare, R. Stalder, A.M. Paunier Doret, M.D. Rozycki, and S.J. Edelstein. 1990. Overexpression of tubulin in yeast; differences in subunit association. Eur. I. Cell Biol. 51: 295-302.

Bresch, C., G. Müller, and R. Egel. 1968. Genes involved in meiosis and sporulation of a yeast. Mol. \& Gen. Genet. 102: 301-306.

Bryan, J., R. Edwards, P. Matsudaira, J. Otto, and J. Wulfkuhle. 1993. Fascin, an echinoid actin-bundling protein, is a homolog of the Drosophila singed gene product. Proc. Natl. Acad. Sci. 90: 9115-9119.

Burke, D., P. Gasdaska, and L. Hartwell. 1989. Dominant effects of tubulin overexpression in Saccharomyces cerevisiae. Mol. Cell. Biol. 9: 1049-1059.

Cant, K., B.A. Knowles, M.S. Mooseker, and L. Cooley. 1994. Drosophila singed, a fascin homolog, is required for actin bundle formation during oogenesis and bristle extension. $/$. Cell Biol. 125: 369-380.

Castrillon, D.H. and S. Wasserman. 1994. diaphanous is required for cytokinesis in Drosophila and shares domains of similarity with the products of the $\lim b$ deformity gene. Development 120: 3367-3377.

Cooley, L., E. Verheyen, and K. Ayers. 1992. chickadee encodes a profilin required for intercellular cytoplasm transport during Drosophila oogenesis. Cell 69: 173-184.

Coutu, M.D. and S.W. Craig. 1988. cDNA-derived sequence of chicken embryos vinculin. Proc. Natl. Acad. Sci. 85: 85358539.

Devereux, J. P. Haeberli, and O. Smithies. 1984. A comprehensive set of sequence analysis programs for the VAX. Nucleic Acids Res. 12: 387-395.

Driever, W. and C. Nüsslein-Volhard. 1988a. A gradient of bicoid protein in Drosophila embryos. Cell 54: 83-93.

- 1988b. The bicoid protein determines position in the Drosophila embryo in a concentration-dependent manner. Cell 54: 95-104.

Ephrussi, A. and R. Lehmann. 1992. Induction of germ cell formation by oskar. Nature 358: 387-392.

Ephrussi, A., L.K. Dickinson, and R. Lehmann. 1991. oskar organizes the germ plasm and directs localization of the posterior determinant nanos. Cell 66: 37-50.

Gout, I., R. Dhand, I.D. Hiles, M.J. Fry, G. Panayotou, P. Das, O. Truong, N.F. Totty, J. Hsuan, and G.W. Booker. 1993. The GTPase dynamin binds to and is activated by a subset of $\mathrm{SH} 3$ domains. Cell 75: 25-36.

Gribskov, M. and R. Burgess. 1986. Sigma factors from E. coli, B. subtilis, phage SP01, and phage T4 are homologous proteins. Nucleic Acids Res. 16: 6745-6763.

Gutzeit, H. 1986a. The role of microtubules in the differentiation of ovarian follicles during vitellogenesis in Drosophila. Wilhelm Roux's Arch. Dev. Biol. 195: 173-181.

- 1986b. Transport of molecules and organelles in meroistic ovarioles of insects. Differentiation 31: 155-165.

Haenlin, M., C. Roos, A. Cassab, and E. Mohier. 1987. Oocytespecific transcription of $f_{s}(1)$ K10: A Drosophila gene affect- ing dorsal-ventral developmental polarity. EMBO /. 6: 801807.

Hay, B., L. Ackerman, S. Barbel, L. Jan, and Y. Jan. 1988. Identification of a component of Drosophila polar granules. Development 103: 625-640.

Jackson-Grusby, L., A. Kuo, and P. Leder. 1992. A variant limb deformity transcript expressed in the embryonic mouse limb defines a novel formin. Genes \& Dev. 6: 29-37.

Jongens, T.A., L.D. Ackerman, J.R. Swedlow, L.Y. Jan, and Y.N. Jan. 1994. Germ cell-less encodes a cell type-specific nuclear pore-associated protein and functions early in the germ-cell specification pathway of Drosophila. Genes \& Dev. 8: 21232136.

Jowett, T. 1986. Preparation of nucleic acids. In Drosophila: $A$ practical approach (ed. D.B. Roberts), pp. 275-286. IRL Press, Washington, DC.

Kim-Ha, J., J.L. Smith, and P.M. Macdonald. 1991. oskar mRNA is localized to the posterior pole of the Drosophila oocyte. Cell 66: 23-35.

Knowles, B. and L. Cooley. 1994. The specialized cytoskeleton of the Drosophila egg chamber. Trends Genet. 10: 235-241.

Koch, E.A. and R.H. Spitzer. 1983. Multiple effects of colchicine on oogenesis in Drosophila; Induced sterility and switch of potential oocyte to nurse-cell developmental pathway. Cell Tissue Res. 228: 21-32.

Lasko, P. and M. Ashburner. 1990. Posterior localization of vasa protein correlates with, but is not sufficient for, pole cell development. Genes \& Dev. 4: 905-921.

Lim, W., F. Richards, and R. Fox. 1994. Structural determinants of peptide-binding orientation and of sequence specificity in SH3 domains. Nature 372: 375-379.

Lupas, A., M. Van Dyke, and J. Stock. 1991. Predicting coiled coils from protein sequences. Science 252: 1162-1164.

Mahajan-Miklos, S. and L. Cooley. 1994. The villin-like protein encoded by the Drosophila quail gene is required for actin bundle assembly during oogenesis. Cell 78: 291-301.

Manseau, L.J. and T. Schüpbach. 1989a. The egg came first, of course. Trends Genet. 5: 400-405.

- $1989 \mathrm{~b}$. cappuccino and spire: Two unique maternal-effect loci required for both the anteroposterior and dorsoventral patterns of the Drosophila embryo. Genes \& Dev. 3: 1437-1452.

Marhoul, J.F. and T. Adams. 1995. Identification of developmental regulatory genes in Aspergillus nidulans by overexpression. Genetics 139: 537-547.

Mayer, B. and D. Baltimore. 1994. Signaling through SH2 and SH3 domains. Trends Cell Biol. 3: 8-13.

Musacchio, A., T. Gibson, V. Lehto, and M. Saraste. 1992. SH3an abundant protein domain in search of a function. FEBS Lett. 307: 55-61.

Neuman-Silberberg, F.S., and T. Schüpbach. 1993. The Drosophila dorsoventral patterning gene gurken produces a dorsally localized RNA and encodes a TGF $\alpha$-like protein. Cell 75: 165-174.

Nüsslein-Volhard, C., H.G. Fröhnhofer, and R. Lehmann. 1987. Determination of anteroposterior polarity in Drosophila. Science 238: 1675-1681.

Pawson, T. and G.D. Gish. 1992. SH2 and SH3 domains: From structure to function. Cell 71: 359-362.

Petersen, J., D. Weilguny, R. Egel, and O. Nielsen. 1995. Characterization of fus1 in Schizosaccharomyces pombe: A developmentally controlled function needed for conjugation. Mol. Cell. Biol. 15: 3697-3707.

Pleiman, C.M., W.M. Hertz, and J.C. Cambier. 1994. Activation of phosphatidylinositol-3' kinase by src-family kinase SH3 binding to the p85 subunit. Science 263: 1609-1612. 
Pokrywka, N.J. and E.C. Stephenson. 1995. Microtubules are a general component of mRNA localization systems in Drosophila oocytes. Dev. Biol. 167: 363-370.

Price, J.V., R.J. Clifford, and T. Schüpbach. 1989. The maternal ventralizing locus torpedo is allelic to faint little ball, an embryonic lethal, and encodes the Drosophila EGF receptor homolog. Cell 56: 1085-1092.

Ren, R., J. Mayer, P. Cicchetti, and D. Baltimore. 1993. Identification of a ten-amino acid proline-rich $\mathrm{SH} 3$ binding site. Science 259: 1157-1161.

Sambrook, J., E.F. Fritsch, and T. Maniatis. 1989. Molecular cloning: A laboratory manual. Cold Spring Harbor Laboratory Press, Cold Spring Harbor, New York.

Savant-Bhonsale, S. and D.J. Montell. 1993. torso-like encodes the localized determinant of Drosophila terminal pattern formation. Genes \& Dev. 7: 2548-2555.

Schejter, E.D. and B.Z. Shilo. 1989. The Drosophila EGF receptor homolog (DER) is allelic to faint little ball, a locus essential for embryonic development. Cell 56: 1093-1114.

Schüpbach, T. 1987. Germ line and soma cooperate during oogenesis to establish the dorsoventral pattern of egg shell and embryo in Drosophila melanogaster. Cell 49: 699-707.

Smith, J.L., J.E. Wilson, and P.M. Macdonald. 1992. Overexpression of oskar directs ectopic activation of nanos and presumptive pole cell formation in Drosophila embryos. Cell 70: 849-859.

Sparks, A.B., L.A. Quilliam, J.M. Thorn, C.J. Der, and B.K. Kay. 1994. Identification and characterization of Src SH3 ligands from phage-displayed random peptide libraries. /. Biol. Chem. 269: 23853-23856.

St. Johnston, D., D. Beuchle, and C. Nüsslein-Vollhard. 1991. Staufen, a gene required to localize maternal RNAs in the Drosophila egg. Cell 66: 51-63.

Stein, D., S. Roth, E. Vogelsang, and C. Nüsslein-Volhard. 1991. The polarity of the dorsoventral axis in the Drosophila embryo is defined by an extracellular signal. Cell 65: 725-735.

Stevens, L.M., H.G. Fröhnhofer, M. Klingler, and C. NüssleinVolhard. 1990. Localized requirement for torso-like expression in follicle cells for development of terminal anlagen of the Drosophila embryo. Nature 346: 660-663.

Tanaka, M. and H. Shibata. 1985. Poly (L-proline)-binding proteins from chick embryos are profilin and profilactin. Eur. J. Biochem. 151: 291-297.

Tautz, D. and C. Pfeifle. 1989. A non-radioactive in situ hybridization protocol for the localization of specific RNAs in Drosophila embryos reveals translational control of the segmentation gene hunchback. Chromosoma 98: 81-85.

Theurkauf, W. 1994. Premature microtubule-dependent cytoplasmic streaming in cappuccino and spire mutant oocytes. Science 265: 2093-2095.

Theurkauf, W.E., S. Smiley, M.L. Wong, and B.M. Alberts. 1992. Reorganization of the cytoskeleton during Drosophila oogenesis: Implications for axis specification and intercellular transport. Development 115: 923-936.

Towbin, H., T. Staehelin, and J. Gordon. 1979. Electrophoretic transfer of proteins from polyacrylamide gels to nitrocellulose sheets: Procedure and some applications. Proc. Natl. Acad. Sci. 76: 4350-4354.

Trumpp, A., P. Blundell, J. de la Pompa, and R. Zeller. 1992. The chicken limb deformity gene encodes nuclear proteins expressed in specific cell types during morphogenesis. Genes \& Dev. 6: 14-28.

Vogt, ,T. F., L. Jackson-Grusby, J. Rush, and P. Leder. 1993. Formins: Phosphoprotein isoforms encoded by the mouse limb deformity locus. Proc. Natl. Acad. Sci. 90: 5554-5558.

Wang, C. and R. Lehmann. 1991. Nanos is the localized poste- rior determinant in Drosophila. Cell 56: 637-647.

Wieschaus, E. and C. Nüsslein-Volhard. In Drosophila: A practical approach (ed. D.B. Roberts), pp. 199-227. IRL Press, Washington, D.C.

Woychik, R., R. Maas, R. Zeller, T. Vogt, and P. Leder. 1990. Formins: Proteins deduced from the alternative transcripts of the limb deformity gene. Nature 346: 850-855.

Xue, F. and L. Cooley. 1993. kelch encodes a component of intercellular bridges in Drosophila egg chambers. Cell 72: 681-693.

Yu, H., J.K. Chen, S. Feng, D.C. Dalgarno, A.W. Brauer, and S.L. Schreiber. 1994. Structural basis for the binding of prolinerich peptides to SH3 domains. Cell 76: 933-945.

Yue, L. and A.C. Spradling. 1992. hu-li tai shao, a gene required for ring canal formation during Drosophila oogenesis, encodes a homolog of adducin. Genes \& Dev. 6: 2443-2454.

Zeller, R., L. Jackson-Grusby, and P. Leder. 1989. The limb deformity gene is required for apical ectodermal ridge differentiation and anteroposterior limb pattern formation. Genes \& Dev. 3: 1481-1492. 


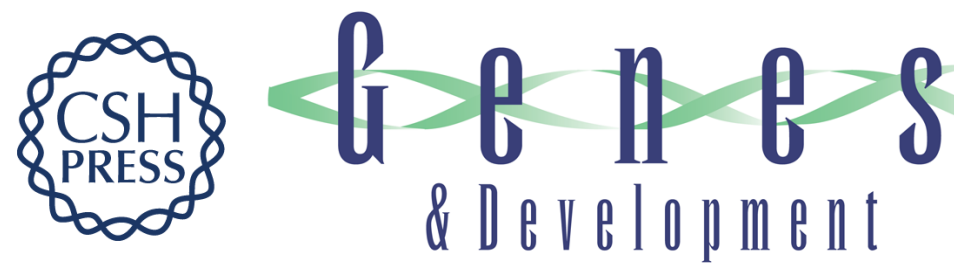

\section{Cappuccino, a Drosophila maternal effect gene required for polarity of the egg and embryo, is related to the vertebrate limb deformity locus.}

S Emmons, H Phan, J Calley, et al.

Genes Dev. 1995, 9:

Access the most recent version at doi:10.1101/gad.9.20.2482

References This article cites 66 articles, 26 of which can be accessed free at:

http://genesdev.cshlp.org/content/9/20/2482.full.html\#ref-list-1

License

Email Alerting Receive free email alerts when new articles cite this article - sign up in the box at the top Service right corner of the article or click here.

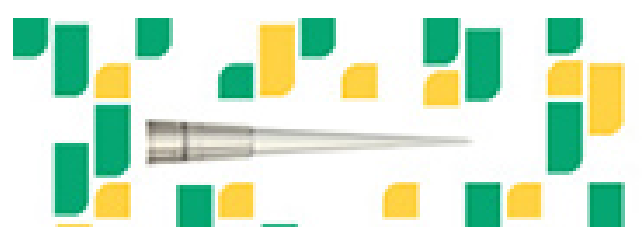

Focused on your science. 